\title{
Surface Plasmon-Induced Band Gap in the Photocurrent Response of Organic Solar Cells
}

\author{
Ribal Georges Sabat, ${ }^{1}$ Marcos Jose Leite Santos, ${ }^{2}$ and Paul Rochon ${ }^{2}$ \\ ${ }^{1}$ Department of Physics, Royal Military College of Canada, P.O. Box 17000, STN Forces, Kingston, ON, Canada K7K 7B4 \\ ${ }^{2}$ Instituto de Física de São Carlos, Universidade de São Paulo, CP 369, 13566-590 São Carlos, SP, Brazil
}

Correspondence should be addressed to Ribal Georges Sabat, sabat@rmc.ca

Received 14 September 2010; Revised 12 November 2010; Accepted 8 December 2010

Academic Editor: Mark van der Auweraer

Copyright (C) 2010 Ribal Georges Sabat et al. This is an open access article distributed under the Creative Commons Attribution License, which permits unrestricted use, distribution, and reproduction in any medium, provided the original work is properly cited.

\begin{abstract}
A $260 \mathrm{~nm}$ layer of organic bulk heterojunction blend of the polymer poly(3-hexylthiophene) (P3HT) and the fullerene [6,6]phenyl $\mathrm{C}_{61}$-butyric (PCBM) was spin-coated in between aluminum and gold electrodes, respectively, on top of a laser inscribed azo polymer surface-relief diffraction grating. Angle-dependent surface plasmons (SPs) with a large band gap were observed in the normalized photocurrent by the P3HT-PCBM layer as a function of wavelength. The SP-induced photocurrents were also investigated as a function of the grating depth and spacing.
\end{abstract}

\section{Introduction}

In the recent years, research on photovoltaic cells has spread beyond inorganic materials, especially in the advent of thinfilm solar cells. Despite their low efficiency, organic solar cells have generated much research interest, mainly because of their ease of fabrication and processability [1-3]. The bulk heterojunction blend of the polymer poly(3-hexylthiophene) and the fullerene $[6,6]$-phenyl $\mathrm{C}_{61}$-butyric (P3HT-PCBM) is one of the most promising organic solar cell materials [4]. The P3HT is a conducting polymer that produces the photovoltaic effect via the excitation of the $\pi$-orbit electrons, while the PCBM possesses a high hole mobility and acts as an acceptor. The P3HT is the hole conductor while the PCBM is the electron conductor [5]. Many papers have reported on how the photovoltaic properties of the P3HTPCBM blend can be enhanced depending on the sample preparation conditions, such as thermal annealing $[6,7]$ and its concentration in solvent [8]. Other papers have also reported on how to further increase the efficiency and the challenges present with these bulk heterojunction cells [9-11].

Since thin-film solar cells have a thickness in the order of a micron or less, wavelength-sized structures can be used to trap light inside the photovoltaic film. The integration of diffraction gratings either in the substrate or in the solar cell material itself has been successfully studied in thin-film silicon cells $[12,13]$ and in organic solar cells $[14,15]$.

Surface plasmons (SPs), which are electromagnetic waves that propagate at the interface between a metal and a dielectric, have also proved to increase light entrapment and absorption in both silicon [16-18] and organic thinfilm solar cells [19-22]. Surface plasmons can be excited by matching the momentum and energy of the incident light beam to that of the plasmon along the direction of propagation. This can be done using a corrugated relief grating as well as metallic nanoparticles. In the absence of a band gap, the surface plasmon wave number $k_{\mathrm{SP}}$ for a flat surface is given by the following dispersion relation:

$$
k_{\mathrm{SP}}=k \sqrt{\frac{\varepsilon_{m} \varepsilon_{d}}{\varepsilon_{m}+\varepsilon_{d}}},
$$

where $k$ is the light wave number propagating in a dielectric with refractive index $n$, where $k=\left(2 \pi / \lambda_{0}\right) n$, and $\varepsilon_{m}$ and $\varepsilon_{d}$ are the permittivities of the metal and the dielectric material respectively. Since $n=\sqrt{\varepsilon_{d}}$ and usually $\sqrt{\varepsilon_{m} /\left(\varepsilon_{m}+n^{2}\right)} \approx 1.1$, for a quick estimate of the resonance wavelength, (1) can be approximated to

$$
k_{\mathrm{sp}} \approx 1.1 n k \text {. }
$$




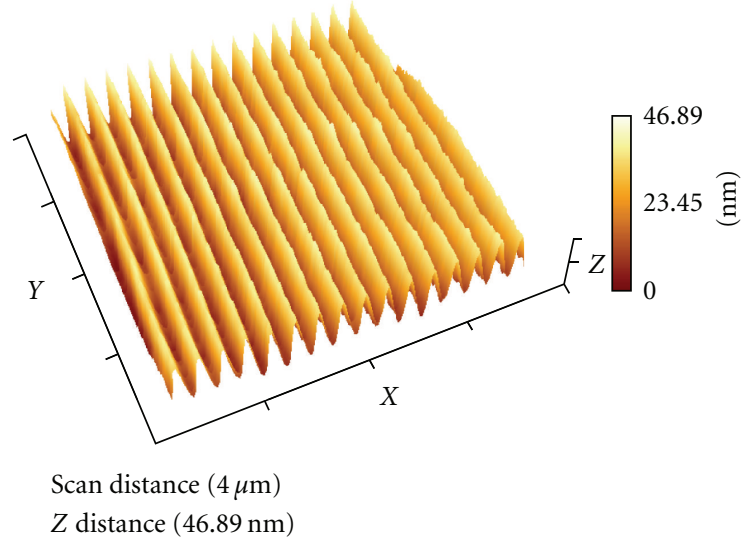

FIGURE 1: AFM picture of a surface relief diffraction grating with $\Lambda=250 \mathrm{~nm}$.

In order for the SP to be generated, its wave number must be phase-matched to that of the incident light beam using, for instance, a diffraction grating, such that along the horizontal $(x)$ direction on the sample surface

$$
k_{\text {light }}=\left|k \sin \theta \pm \frac{2 \pi m}{\Lambda}\right|,
$$

where $\Lambda$ is the grating spacing, $\theta$ is the incidence angle, and $m$ is an integer. A positive diffraction order indicates forward coupling, while the negative order represents backward coupling. On a surface-relief grating, only light polarized in the direction of the grating vector has an electric field component perpendicular to the metal surface and therefore can couple to an SP mode. Hence, if a sample is rotated around the vertical $(y)$ axis, only horizontally $(x)$ polarized light $(\mathrm{TM})$ will generate a surface plasmon. For normal incidence and first order diffraction $(m=1)$, (3) becomes

$$
k_{\mathrm{sp}} \approx 1.1 n k \approx\left|\frac{2 \pi}{\Lambda}\right|
$$

Therefore, the surface plasmon resonance wavelength should be

$$
\lambda_{\mathrm{SP}} \approx 1.1 n \Lambda
$$

Nonetheless, photonic band gaps have also been observed in the propagation of SPs on periodic media, and their physical origin was explained [23]. Therefore, theoretical predictions of the surface plasmon wavelength can only be useful for finding the centre of the surface plasmon band gap. The band gap width has also been shown to depend on the gratings' depth.

In this paper, we use surface-relief diffraction gratings inscribed on poly $\left(4^{\prime}-\{[2-\right.$ (acryloyloxy)thel $]$ ethyl-amino $\}-4-$ nitroazobenzene) (pDR1A), also called azo polymer [24], to induce SPs at the interface between the aluminum electrode and the P3HT-PCBM blend. The SPs were measured as a function of the incidence angle and the wavelength of the incoming light. The effects of the gratings'

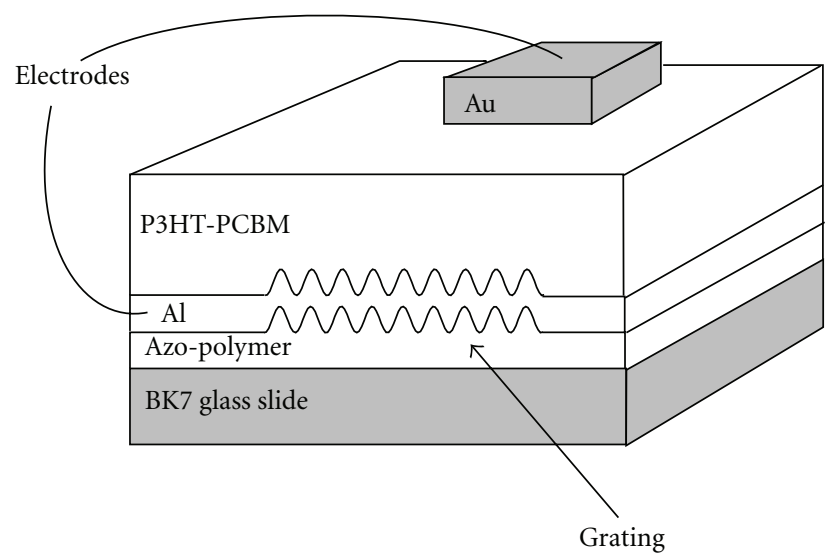

Figure 2: A cut-away side view of the test sample.

depth and spacing on the SP photocurrent were also investigated.

\section{Experiment}

The azo-polymer compound was diluted in dichloromethane with a mix ratio of $3 \%$ weight/weight, and thoroughly mixed. A $200 \mathrm{~nm}$ layer of this solution was spin-coated on a BK7 glass slide. Surface-relief gratings were written on the azo-polymer films by direct holographic exposure to the interference pattern of two coherent light beams at $\lambda=$ $458 \mathrm{~nm}$. The grating spacing can easily be controlled by changing the incidence angle of the interfering beams, while the depth of the gratings was dependent on the exposure time, as described elsewhere [25]. Figure 1 shows an atomic force microscope picture of a diffraction grating written with spacing, $\Lambda=250 \mathrm{~nm}$. An aluminum electrode with $100 \mathrm{~nm}$ thickness was subsequently evaporated on the diffraction grating. As for the photovoltaic blend, a (1:1) P3HT-PCBM solution was diluted in chlorobenzene with a mix ratio of $5 \%$ weight/weight. This solution was thoroughly mixed using an ultrasonic bath and a mechanical shaker. The P3HTPCBM blend was then spin-coated on top of the aluminum electrode with a thickness of approximately $260 \mathrm{~nm}$, and annealed at $95^{\circ} \mathrm{C}$ for 1 hour under $\mathrm{N}_{2}$ atmosphere. Finally, a very thin $(10 \mathrm{~nm})$ layer of gold was evaporated on top of the P3HT-PCBM layer. A cut-away view of the experimental sample is illustrated in Figure 2. The illuminated section of the active layer was approximately $2 \times 4 \mathrm{~mm}^{2}$.

Since gold absorbs strongly below the wavelength of $\lambda=600 \mathrm{~nm}$, it was found better to use the aluminum to generate the SP. The aluminum and gold electrodes were essential parts of harvesting the highest photovoltaic signal from the P3HT-PCBM blend because of the energy band compatibility of the structure.

As for the experimental setup seen in Figure 3, the light from a spectrometer passed through a mechanical chopper was collimated by a concave mirror, passed though a polarizer, and was finally incident on the test sample, which was located on a computer-controlled turn table. 


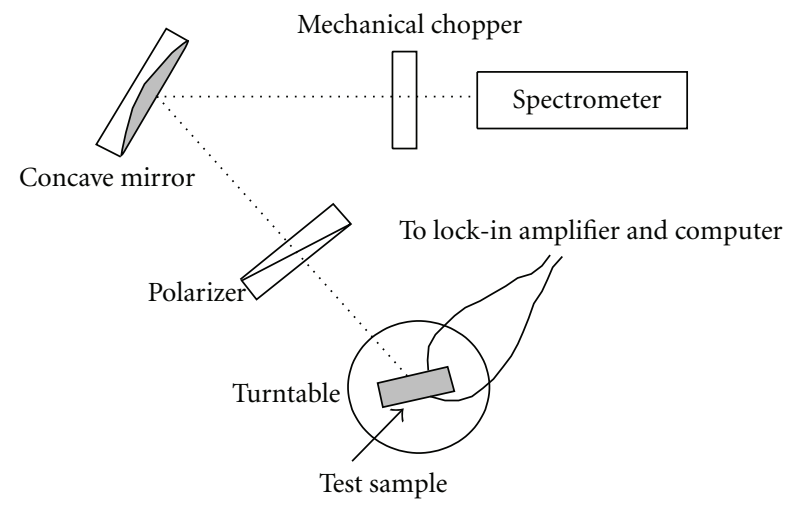

Figure 3: The experimental setup.

The signal from the organic solar cell was amplified by a lockin amplifier and recorded on a computer.

\section{Results and Analysis}

A preliminary plot in Figure 4 shows the photocurrent response of the test sample at normal incidence on an area with no diffraction grating. It can clearly be seen that TE and TM light polarizations have near identical curves. As discussed in the previous section, we expect the SP to be generated only with TM polarized light, which has its electric field vector oscillating perpendicular to the grating's peaks and troughs. This is evident in Figure 5 where we repeated the photocurrent measurement on a grating with spacing $\Lambda=250 \mathrm{~nm}$ and a depth of approximately $50 \mathrm{~nm}$ at normal incidence. The TE photocurrent response curve stays the same, while a large increase was measured in the TM curve. Two peaks can be identified at $\lambda=432 \mathrm{~nm}$ and $\lambda=569 \mathrm{~nm}$ these peaks are associated with a photonic band gap in the SP dispersion curve. In order to confirm that these peaks are SP-induced, the photocurrent response of the P3HT-PCBM blend was measured on a grating with spacing $\Lambda=325 \mathrm{~nm}$ and a depth of approximately $15 \mathrm{~nm}$ at normal incidence, as seen in Figure 6. A similar increase was found for the TM polarization, but the peaks has clearly shifted and one of them is now located at $\lambda=$ $585 \mathrm{~nm}$.

According to Moul and Meerholz [26], the refractive index of $1: 1 \mathrm{P} 3 \mathrm{HT}-\mathrm{PCBM}$ is around 1.75 at $500 \mathrm{~nm}$ and 2 at $700 \mathrm{~nm}$. Therefore, using (5), for diffraction gratings with $\Lambda=250 \mathrm{~nm}$ and $\Lambda=325 \mathrm{~nm}$, surface plasmons should be centered around $480 \mathrm{~nm}$ and $715 \mathrm{~nm}$, respectively. This is seen in Figure 5 since the band gap centre is clearly located at $500 \mathrm{~nm}$. However, in Figure 6, only the lower wavelength resonance peak can be seen. This is because the band gap centre for a $325 \mathrm{~nm}$ grating should be at around $715 \mathrm{~nm}$, and the higher resonance peak is located above the absorption range of the active layer.

As we change the incidence angle on the $250 \mathrm{~nm}$ grating with $50 \mathrm{~nm}$ depth, seen in Figure 7, the SP-induced peaks

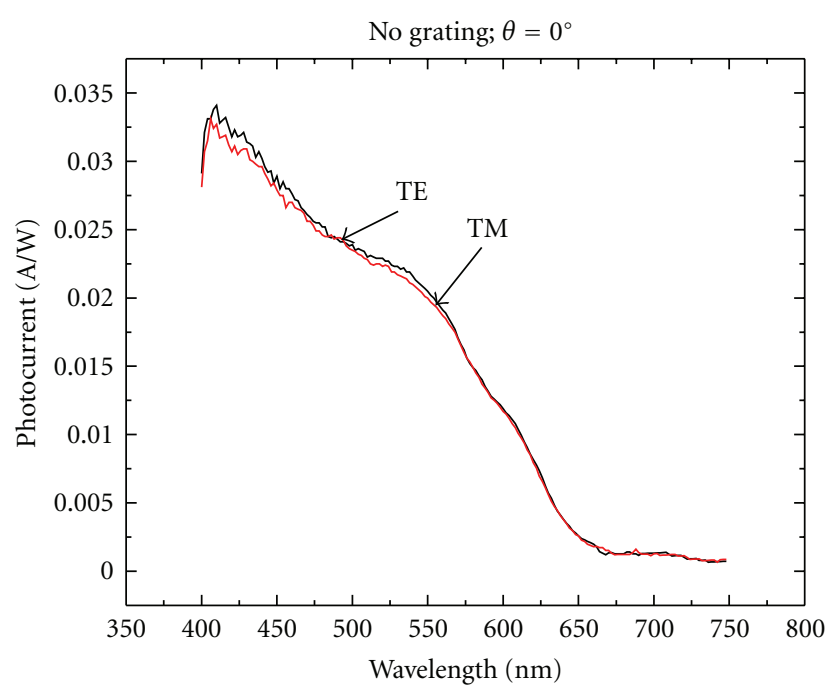

FIgure 4: The TE and TM photocurrent responses of the P3HTPCBM layer as a function of wavelength with no grating and at normal incidence.

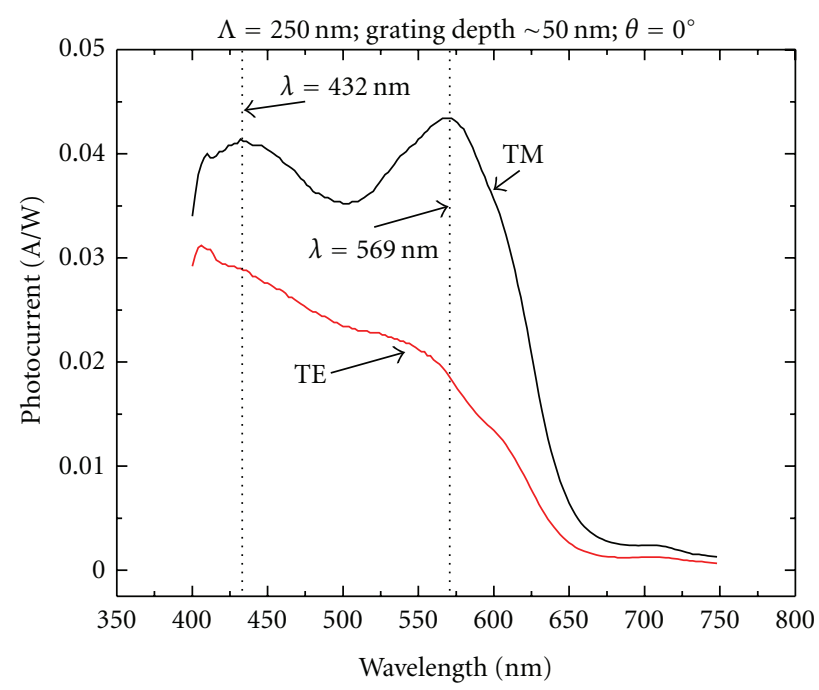

Figure 5: The TE and TM photocurrent responses of the P3HTPCBM layer as a function of wavelength with $\Lambda=250 \mathrm{~nm}$ and at normal incidence.

in the photocurrent for TM polarized light seem to shift as a function of the angle. This confirms that this is in fact a photonic band gap measured in the photocurrent response of the bulk heterojunction blend. The lower wavelength peaks are associated with forward coupling of light, while the higher wavelength peaks are associated with backward coupling in the active layer, in accordance with (3), as explained elsewhere [27]. The dispersion relation was subsequently plotted using (3) in Figure 8 for two different gratings with $250 \mathrm{~nm}$ spacing and with grating depths of 50 and $28 \mathrm{~nm}$. The band gap becomes easily distinguishable and appears to decrease as the grating depth decreases. 


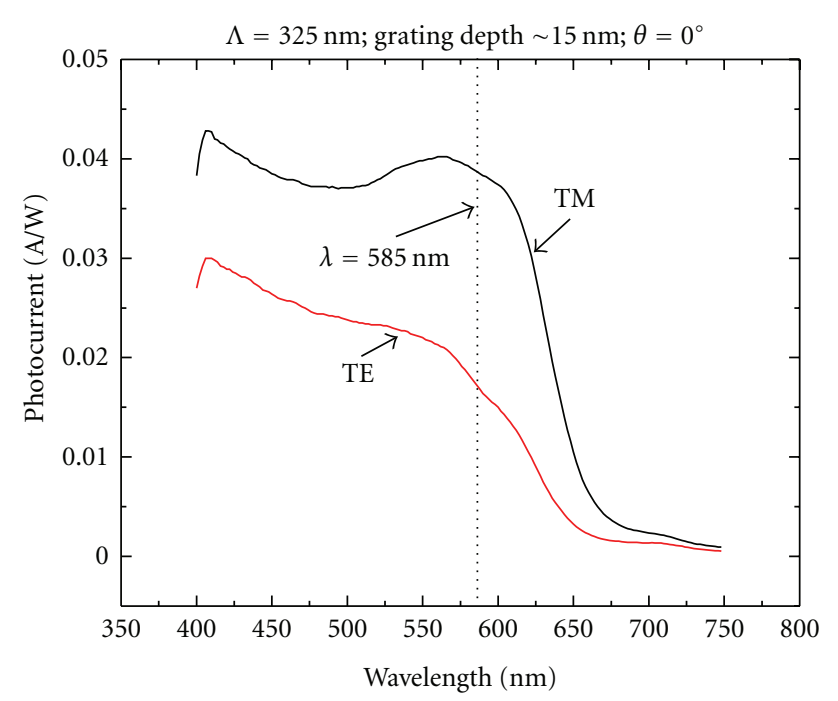

Figure 6: The TE and TM photocurrent responses of the P3HTPCBM layer as a function of wavelength with $\Lambda=325 \mathrm{~nm}$ and at normal incidence.

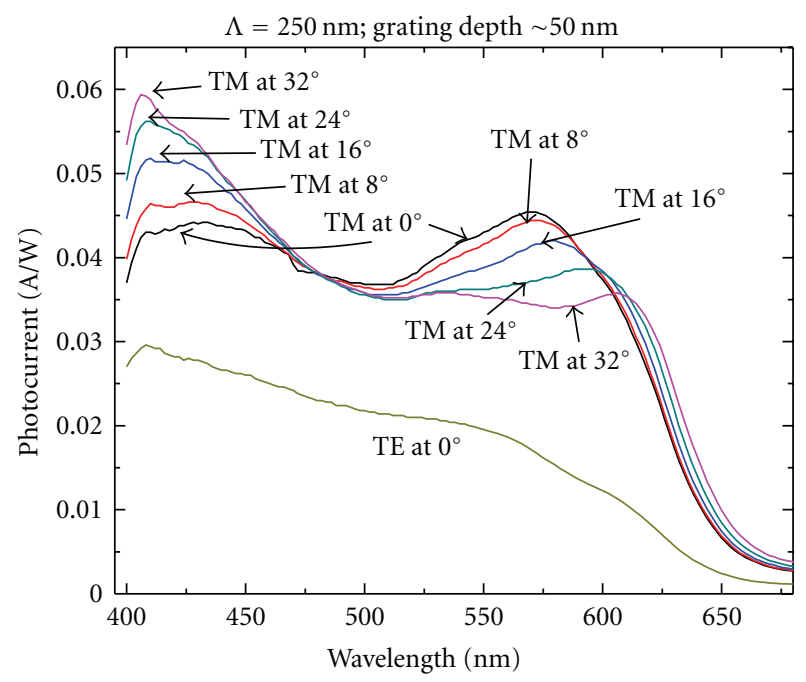

FIgUre 7: The TE and TM photocurrent responses of the P3HTPCBM layer as a function of wavelength with $\Lambda=250 \mathrm{~nm}$ and at various incidence angles.

This result is inline with the previous publications [23]. Finally, Figure 9 shows the relative photocurrent response (TM/TE) for gratings with $250 \mathrm{~nm}$ spacing and decreasing depths. The highest increase in photocurrent was found to be 2.72 at a wavelength of $618 \mathrm{~nm}$ for a grating depth of $50 \mathrm{~nm}$. It can also be seen that as the grating depth decreases, so does the photocurrent for this particular grating spacing.

Further research is currently being conducted in our laboratory on the effects of cross-corrugated and parallel super-imposed gratings with different spacing on the SP-induced enhancements in the photocurrent response.

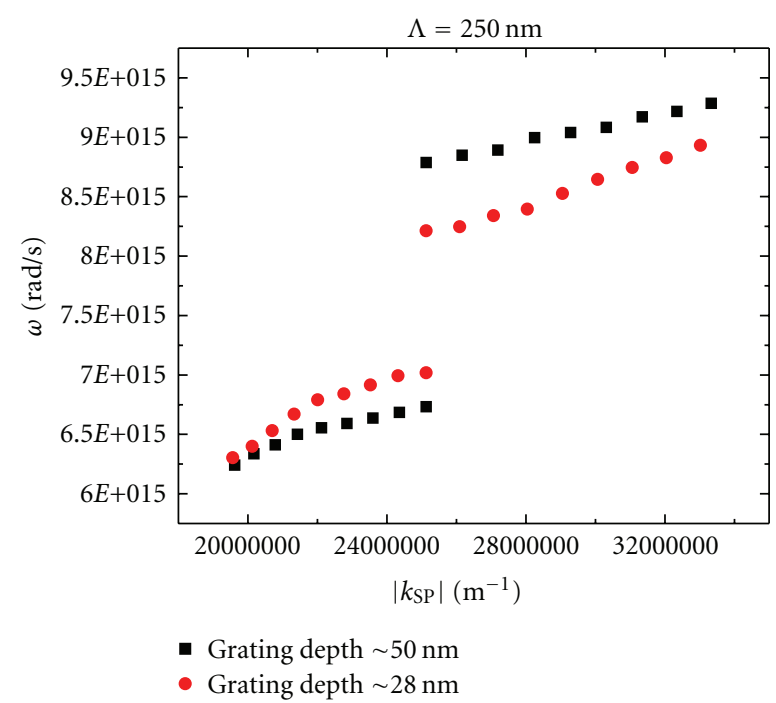

FIGURE 8: The dispersion relation plot for gratings with $\Lambda=250 \mathrm{~nm}$ and various depths.

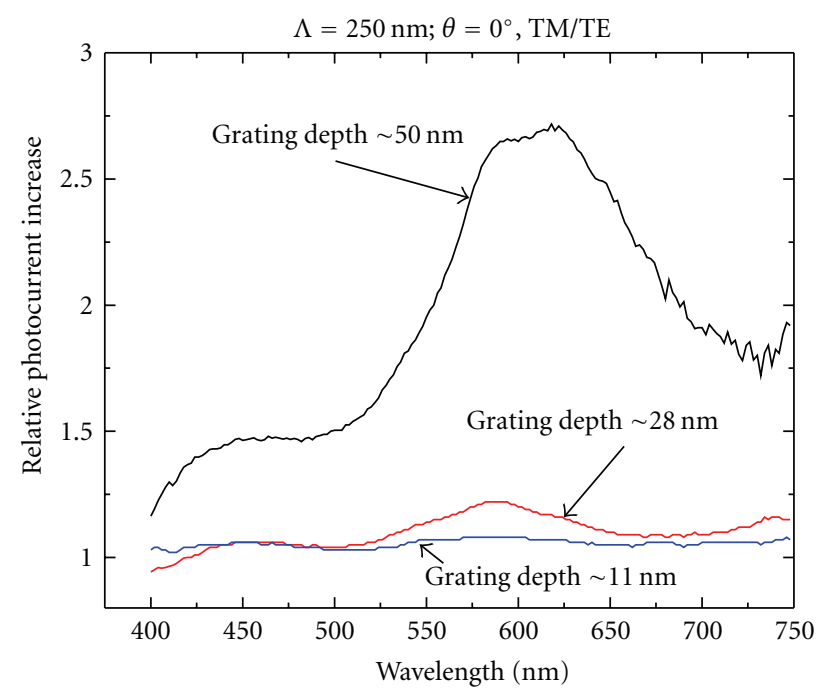

FIGURE 9: The relative photocurrent responses of P3HT-PCBM layer as a function of wavelength at normal incidence for gratings with $\Lambda=250 \mathrm{~nm}$ and at various depths.

This will allow tailoring the photocurrent increase over a larger wavelength range.

\section{Conclusion}

In this experiment, corrugated gratings were used to generate surface plasmons within the range of 450 to $650 \mathrm{~nm}$. These angle-dependent SP resonances increased the local electromagnetic field at the boundary between the P3HT-PCBM and aluminum layers, hence increasing the photocurrent generated. A photonic band gap was also apparent in the measurements and it seemed to depend on the grating depth. 


\section{Acknowledgment}

The authors acknowledge the funding from the Natural Sciences and Engineering Research Council of Canada (NSERC).

\section{References}

[1] A. J. Heeger, "Semiconducting polymers: the third generation," Chemical Society Reviews, vol. 39, no. 7, pp. 2354-2371, 2010.

[2] C. Winder and N. S. Sariciftci, "Low bandgap polymers for photon harvesting in bulk heterojunction solar cells," Journal of Materials Chemistry, vol. 14, no. 7, pp. 1077-1086, 2004.

[3] M. J. L. Santos, J. Ferreira, E. Radovanovic, R. Romano, O. L. Alves, and E. M. Girotto, "Enhancement of the photoelectrochemical response of poly(terthiophenes) by $\mathrm{CdS}(\mathrm{ZnS})$ coreshell nanoparticles," Thin Solid Films, vol. 517, no. 18, pp. 5523-5529, 2009.

[4] D. Chirvase, Z. Chiguvare, M. Knipper, J. Parisi, V. Dyakonov, and J. C. Hummelen, "Electrical and optical design and characterisation of regioregular poly(3-hexylthiophene2,5diyl)/fullerene-based heterojunction polymer solar cells," Synthetic Metals, vol. 138, no. 1-2, pp. 299-304, 2003.

[5] N. C. Greenham, X. Peng, and A. P. Alivisatos, "Charge separation and transport in conjugated-polymer/semiconductornanocrystal composites studied by photoluminescence quenching and photoconductivity," Physical Review B, vol. 54, no. 24 , pp. $17628-17637,1996$.

[6] M. Reyes-Reyes, K. Kim, and D. L. Carroll, "High-efficiency photovoltaic devices based on annealed poly(3hexylthiophene) and 1-(3-methoxycarbonyl)-propyl-1-phenyl- $(6,6) \mathrm{C}_{61}$ blends," Applied Physics Letters, vol. 87, no. 8, pp. 1-3, 2005.

[7] Y. Kim, S. A. Choulis, J. Nelson, D. D. C. Bradley, S. Cook, and J. R. Durrant, "Device annealing effect in organic solar cells with blends of regioregular poly(3-hexylthiophene) and soluble fullerene," Applied Physics Letters, vol. 86, no. 6, Article ID 063502, 3 pages, 2005.

[8] W. H. Baek, H. Yang, T. S. Yoon, C. J. Kang, H. H. Lee, and Y. S. Kim, "Effect of P3HT:PCBM concentration in solvent on performances of organic solar cells," Solar Energy Materials and Solar Cells, vol. 93, no. 8, pp. 1263-1267, 2009.

[9] H. Paul, C. David, and B. P. Rand, "Strategies for increasing the efficiency of heterojunction organic solar cells: material selection and device architecture," Accounts of Chemical Research, vol. 42, no. 11, pp. 1740-1747, 2009.

[10] J. L. Brédas, J. E. Norton, J. Cornil, and V. Coropceanu, "Molecular understanding of organic solar cells: the challenges," Accounts of Chemical Research, vol. 42, no. 11, pp. 1691-1699, 2009.

[11] J. Peet, A. J. Heeger, and G. C. Bazan, "'Plastic" solar cells: self-assembly of bulk heterojunction nanomaterials by spontaneous phase separation," Accounts of Chemical Research, vol. 42, no. 11, pp. 1700-1708, 2009.

[12] R. Dewan and D. Knipp, "Light trapping in thin-film silicon solar cells with integrated diffraction grating," Journal of Applied Physics, vol. 106, no. 7, Article ID 074901, 2009.

[13] I. Tobías, A. Luque, and A. Martí, "Light intensity enhancement by diffracting structures in solar cells," Journal of Applied Physics, vol. 104, no. 3, Article ID 034502, 2008.
[14] S. I. Na, S. S. Kim, J. Jo, S. H. Oh, J. Kim, and D. Y. Kim, "Efficient polymer solar cells with surface relief gratings fabricated by simple soft lithography," Advanced Functional Materials, vol. 18, no. 24, pp. 3956-3963, 2008.

[15] S. D. Zilio, K. Tvingstedt, O. Inganäs, and M. Tormen, "Fabrication of a light trapping system for organic solar cells," Microelectronic Engineering, vol. 86, no. 4-6, pp. 1150-1154, 2009.

[16] K. R. Catchpole and A. Polman, "Plasmonic solar cells," Optics Express, vol. 16, no. 26, pp. 21793-21800, 2008.

[17] Y. A. Akimov, K. Ostrikov, and E. P. Li, "Surface plasmon enhancement of optical absorption in thin-film silicon solar cells," Plasmonics, vol. 4, no. 2, pp. 107-113, 2009.

[18] S. Pillai, K. R. Catchpole, T. Trupke, and M. A. Green, "Surface plasmon enhanced silicon solar cells," Journal of Applied Physics, vol. 101, no. 9, Article ID 093105, 2007.

[19] K. Tvingstedt, N. K. Persson, O. Inganäs, A. Rahachou, and I. V. Zozoulenko, "Surface plasmon increase absorption in polymer photovoltaic cells," Applied Physics Letters, vol. 91, no. 11, Article ID 113514, 2007.

[20] D. Duche, P. Torchio, L. Escoubas et al., "Improving light absorption in organic solar cells by plasmonic contribution," Solar Energy Materials and Solar Cells, vol. 93, no. 8, pp. 13771382, 2009.

[21] J. K. Mapel, M. Singh, M. A. Baldo, and K. Celebi, "Plasmonic excitation of organic double heterostructure solar cells," Applied Physics Letters, vol. 90, no. 12, Article ID 121102, 2007.

[22] N. C. Lindquist, W. A. Luhman, S. H. Oh, and R. J. Holmes, "Plasmonic nanocavity arrays for enhanced efficiency in organic photovoltaic cells," Applied Physics Letters, vol. 93, no. 12, Article ID 123308, 2008.

[23] W. L. Barnes, T. W. Preist, S. C. Kitson, and J. R. Sambles, "Physical origin of photonic energy gaps in the propagation of surface plasmons on gratings," Physical Review B, vol. 54, no. 9, pp. 6227-6244, 1996.

[24] A. Natansohn, S. Xie, and P. Rochen, "Azo polymers for reversible optical storage. 2. Poly[4'-[[2-(acryloyloxy)ethyl] ethylamino]-2-chloro-4-nitroazobenzene]," Macromolecules, vol. 25, no. 20, pp. 5531-5532, 1992.

[25] P. Rochon, J. Mao, A. Natansohn, and E. Batalla, "Optically induced high efficiency gratings in azo polymer films," Polymer Preprints, vol. 35, p. 154, 1994.

[26] A. J. Moul and K. Meerholz, "Interference method for the determination of the complex refractive index of thin polymer layers," Applied Physics Letters, vol. 91, no. 6, Article ID 061901, 2007.

[27] L. Lévesque and P. Rochon, "Surface plasmon photonic bandgap in azopolymer gratings sputtered with gold," Journal of the Optical Society of America A, vol. 22, no. 11, pp. 25642568, 2005. 


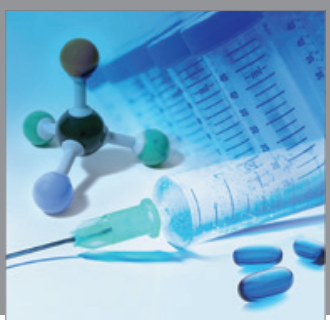

International Journal of

Medicinal Chemistry

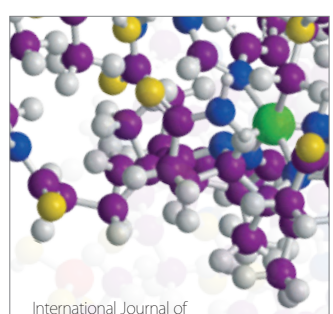

Carbohydrate Chemistry

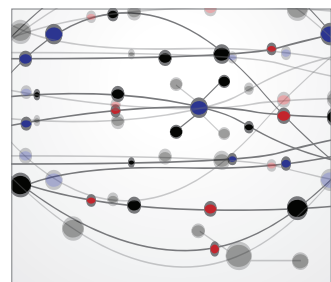

The Scientific World Journal
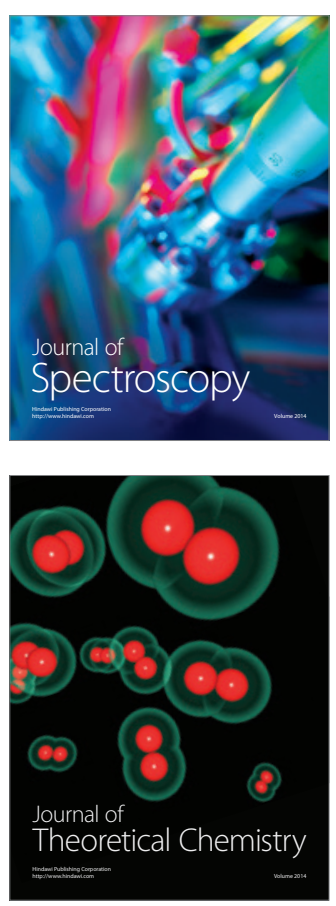
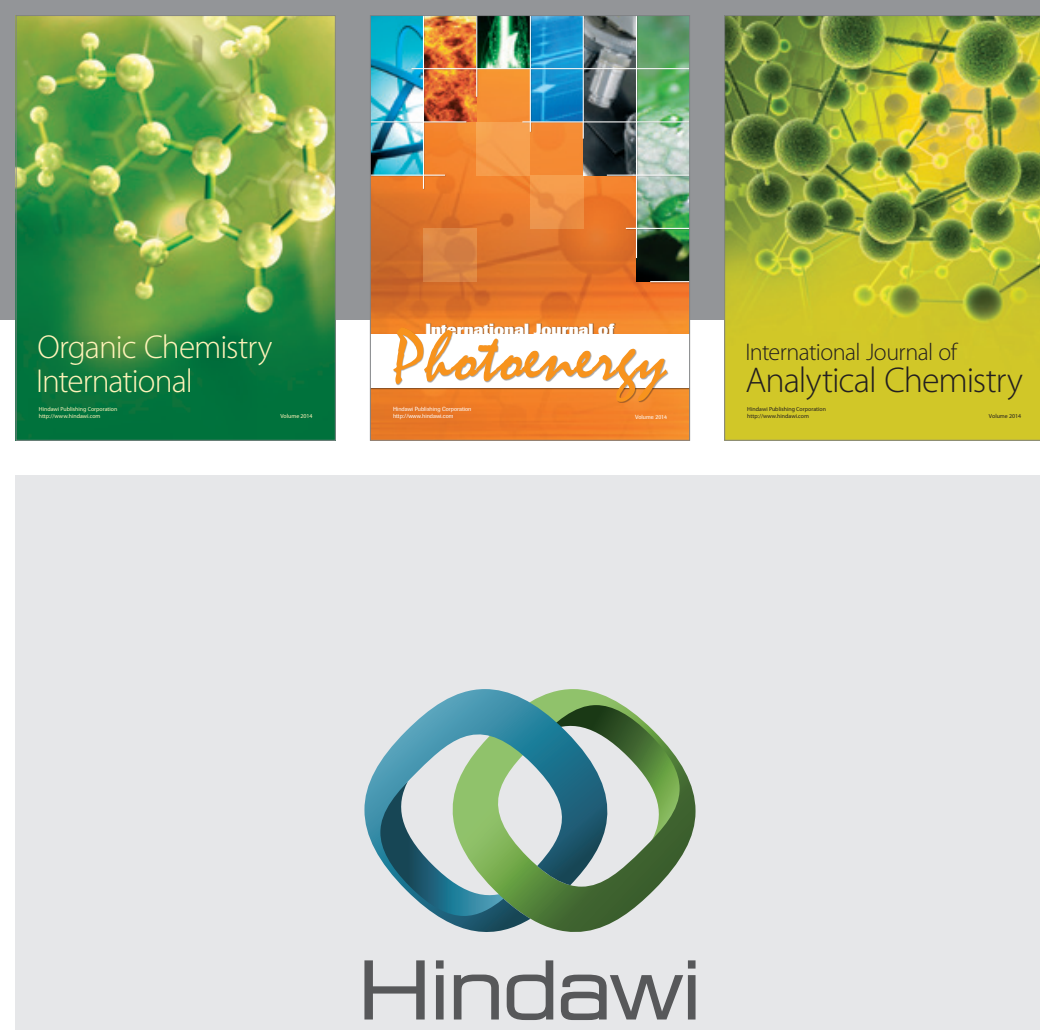

Submit your manuscripts at

http://www.hindawi.com
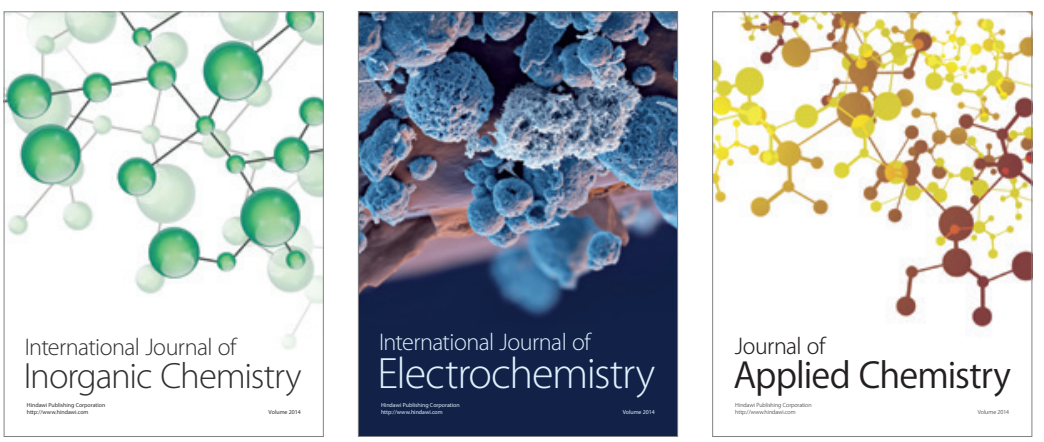

Journal of

Applied Chemistry
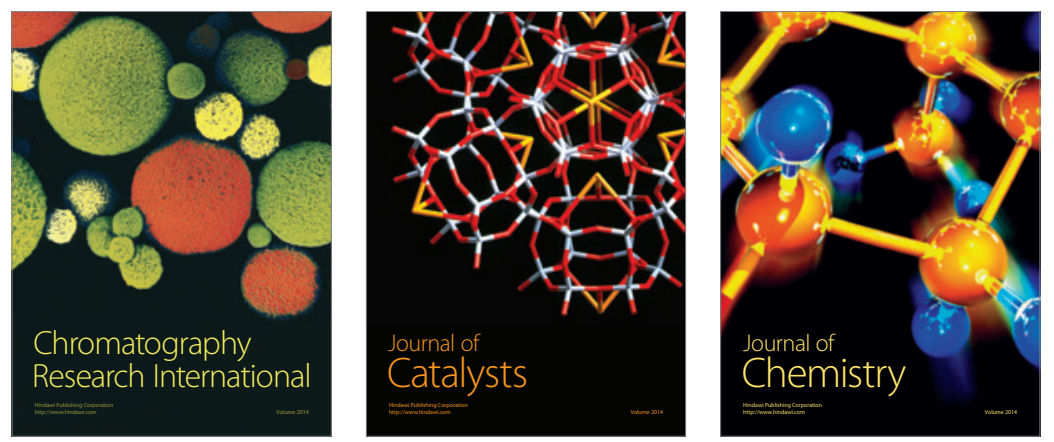
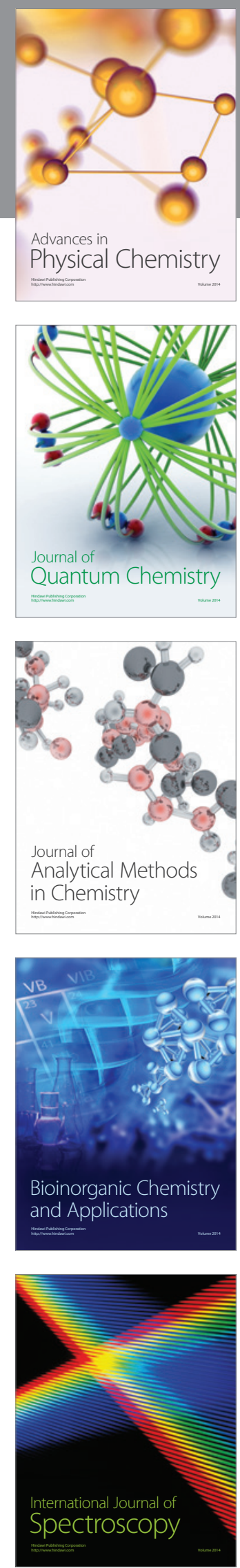